\title{
Cooking and Functional Properties of Parboiled Milled Local Rice Marketed in the South-East Zone of Nigeria
}

\author{
Chinenye E. Azuka ${ }^{a^{*}}$, Iro Nkama ${ }^{\mathrm{a}}$, Chinwendu R. Eze ${ }^{\mathrm{a}}$, Nahemiah Danbaba ${ }^{\mathrm{b}}$, And \\ FELIX U. AsOIro ${ }^{c}$ \\ ${ }^{a}$ Department of Food Science and Technology, University of Nigeria, Nsukka \\ b National Cereals Research Institute (NCRI), Badeggi, P.M.B.8 Bida, Niger State, Nigeria \\ ${ }^{\mathrm{c}}$ Department of Agricultural and Bioresources Engineering, University of Nigeria, Nsukka \\ ${ }^{*}$ Corresponding author \\ chinenye.azuka@unn.edu.ng \\ TEL.: +2347062463026
}

Received: 11 December 2018; Published online: 18 October 2020

(4) Check for updates

\begin{abstract}
Imported rice is perceived to have better cooking properties than locally grown rice in Nigeria and it has increased its market share while reducing patronage for local rice. Rice in Nigeria has many applications, including consumption as whole cooked grain or dumpling or use as an adjunct in making beverages. Eighteen varieties of parboiled milled local rice and three imported rice varieties, coded Ip1, Ip2 and Ip3, were studied for their cooking and functional properties using standard methods. There was a significant $(\mathrm{p}<0.05)$ increase in the dimensions of all the rice varieties when cooked. There was a $25 \mathrm{~g}$ increase in the grain weight and an elongation ratio of more than 1.26 in all the rice varieties. Ghesua had the highest cooked grain weight (68.67 g) while Omor-Mas (6.00) and R-Bus (6.00) had the highest volume expansion ratio (VER). The VER was more than 3.00 for all the rice varieties. All the local rice varieties imbibed less water $(17.67-25.33 \mathrm{ml})$ compared to the imported rice varieties (26.00-27.67ml) before they reached their optimum cooking time. The imported rice varieties were of soft gel consistency $(89.67-73.50 \mathrm{~mm})$ and intermediate amylose content (20.71-23.14 \%) while the local rice varied in amylose and gel consistency. Abakiliki-Mas $(27.00 \mathrm{~mm})$ and R-8 (33.67 mm) were of hard gel-consistency, intermediate $(21.11 \%)$ and high amylose $(27.21 \%)$ content respectively and have not been exploited although they would be appropriate for making canned rice, dry mixes and rice-noodles.
\end{abstract}

Keywords: Oryza sativa L; Dimensions; Elongation ratio; Volume expansion ratio; Gel consistency; Amylose

\section{Introduction}

Rice is the staple food for over 3 billion people, constituting over half of the world's population (Abiona, 2011; Anonymous, 2009; Danbaba et al., 2014; Imolehin \& Wada, 2000; Muthayya, Sugimoto, Montgomery \& Maberly, 2014; Oko \& Ugwu, 2011; Sanusi, Akinoso \& Danbaba, 2017) especially in India, China, other parts of
Asia, and Africa (Akaeze, 2010). Nigeria has been the largest rice producing country in West Africa since 1980 and the third largest in Africa, after Egypt and Madagascar (Imolehin \& Wada, 2000). Since the 1960s when rice was served mainly at banquets and celebrations in Nigeria, it has become one of the basic foods in the $\mathrm{Ni}$ gerians' diet, with consumption rising from 8 $\mathrm{kg}$ per person in 1960 to $27 \mathrm{~kg}$ per person in 
2007 (Diagne, Bamba, Manful \& Ajayi, 2011). This led to importation of rice from Thailand and USA as the quantity produced in Nigeria was not enough for the masses. Today, importation is sustained and imported rice is preferred over local rice in Nigeria because of its cleaner general appearance and perceived better cooking properties than locally grown rice. Rice quality is partially determined by the genetic makeup of a variety but mainly by a variety of subjective and objective factors (Bida, 2013; Mutters \& Thompson, 2009). Among the qualities determined objectively are the cooking and functional properties of the rice grain (Webb, 1972).

Cooking properties' evaluation is essential in order to know the way in which each rice variety will react when heated in boiling water at a temperature of $100 \pm 2^{\circ} \mathrm{C}$. Rice exhibits different characteristics when cooked including tendency to cling together, ability to become fluffy and lie separate, expansion in volume and length, increase in weight and loss of rice solids. Food vendors prefer rice with high volume expansion ratio (VER) in order to increase profit from sales. For increased satiety, rice with higher weight gain is prescribed. In Chinese cuisine, short-grain rice is preferred because the grains are sticky or mushy and are easier to eat with chopsticks (Webb, 1972). In the US, the preference is for long grain rice that becomes fluffy and lies separately when cooked.

Rice is consumed as whole grain cooked rice along with sauce, Jollof or fried rice, local beverages and dumpling in Nigeria. Some of the most important uses and processing applications of rice include boiled or steamed whole-grain rice for consumer use; dry breakfast and babyfood cereals; brewers rice; canned rice such as in soups, puddings and mixes; quick cooking, other convenience and specialty food products; rice flour as a thickener in sauces, gravies and puddings; rice starch for industrial and other processes; and preparations for certain types of fermented foods (Webb, 1972). Amylose content and gel consistency can highly influence processing qualities of rice, which can vary based on the varieties as evaluated by Thomas, WanNadiah and Bhat (2013) for Malaysian rice and Bhonsle and Krishnan (2010) for aromatic rice varieties in Goa India.
There are limited studies and paucity of information on the cooking and functional characteristics of rice milled and consumed in Nigeria (Akaeze, 2010) which makes Nigerians limit their use of local rice and perceive that imported rice has better cooking properties than local rice. It is imperative to evaluate the cooking and functional properties of the rice varieties as this will influence their post-harvest handling (Sanusi et al., 2017). Parameters determined as indices of the cooking properties of rice were physical dimensions, elongation ratio (ER), weight increase (WI), volume expansion ratio (VER), water uptake ratio (WUR), minimum and optimum cooking time, solid loss in water (SLIW) and volume of water absorbed (VWA). Parameters determined as indices of the functional properties were amylose content and gel consistency. The objective of this study was to determine the cooking and functional properties of local rice varieties sold in South-East Nigeria and also establish how they correlate.

\section{Materials and Methods}

\subsection{Materials}

Eighteen varieties of parboiled milled domestic rice were obtained from different rice processing units and markets in Enugu (FARO 44, Fadama, Fortin 16 and Fortin 16, old variety), Anambra (Omor-Mas, R-Bus, FARO 40, Igboukwu rice, Aguleri rice, Taraba rice and B-G) and Ebonyi (Akpujie, kpurukpuru, Afikpo-Mas, Abakiliki Mas, R-8, 306 and Geshua) states as represented in Tables 1-4. Three imported parboiled rice varieties were purchased from Ogige market in the Nsukka Local Government Area of Enugu State, Nigeria. The imported rice varieties served as a control and were coded as Ip1, Ip2, and Ip3. The imported rice varieties were procured based on cost (Ip1), commonly consumed rice variety (Ip2) and difference in length size (Ip3). The samples collected were manually cleaned using plastic trays in order to remove contaminants such as husk, shrivelled kernels (defectives), stones and seeds. All samples were stored at $25 \pm 2^{\circ} \mathrm{C}$, in a moisture free environment, until needed. 


\subsection{Methods}

The cooking method adopted was as described by Odenigbo, Ngadi, Ejebe, Woin and Ndindeng (2014). Four grams of each rice variety were placed in a beaker containing $60 \mathrm{ml}\left(\mathrm{V}_{1}\right)$ of distilled water. The rice grains were cooked in a water bath at $100 \pm 1{ }^{\circ} \mathrm{C}$. Measurements were taken after 10 minutes of cooking and every minute thereafter. The measurements involved collection of 5 grains from the cooking vessel and pressing between two glass slides. The time when a minimum of $95 \%$ of the collected boiled grains no longer displayed an opaque core or un-gelatinized centers was recorded as the Minimum Cooking Time (MCT). The rice was allowed to simmer for another $2 \mathrm{~min}$ to ensure that the core of all grains had been gelatinized. This additional 2 min after the MCT was referred to as Optimum Cooking Time (OCT).

\section{Cooked grain dimensions}

Cooked grain dimensions were determined by the method described by Bida (2013).

\section{Cooked grain length}

Ten cooked whole rice grain samples of each variety were randomly selected and the length of the grains measured using a digital calliper (0.1100mm A\&D Company Limited). The mean value of each variable was determined and noted as $\mathrm{L}_{2}$. The value obtained was recorded as each sample's cooked grain size.

\section{Cooked grain shape}

Ten optimum cooked whole rice grain samples of each variety were randomly selected and the width of the cooked grains were determined using a digital calliper $(0.1-100 \mathrm{~mm}$ A\&D Company Limited) and noted as $\mathrm{Wd}_{2}$. The length/ width ratio of the samples were calculated using Equation (1). The mean value of each variable was obtained and the value obtained was recorded as the grain shape for each sample.

$$
\frac{L}{W}=\frac{L_{2}}{W d_{2}}
$$

\section{Thickness of cooked rice grain}

Ten cooked whole rice grain samples of each variety were randomly selected and the thickness of the grains measured using a digital calliper (0.1-100mm A\&D Company Limited). The mean value was obtained and recorded as each sample's thickness.

\section{One-thousand (1000) cooked grain weight}

One hundred optimum cooked kernel representative sample (triplicates) for each variety were randomly selected. The weight of each sample was determined using a 500g capacity weighing scale (Electronic Pocket Scale Model EHA251). The value obtained was multiplied by 10 . The cooked 1000 kernel mean weight of the samples were obtained and noted as $\mathrm{W}_{2}$.

\section{Volume of cooked grains (VCG)}

Volume of cooked grains $\left(\mathrm{V}_{2} \mathrm{ml}\right)$ was determined by a displacement method as described by Gariboldi (1979). The optimum cooked rice grains were removed from the water bath and allowed to drain off excess water. The wet cooked grains were placed on filter paper to blot out excess water. One hundred cooked grains were counted and put in a measuring cylinder containing $20 \mathrm{ml}$ of water $\left(\mathrm{V}_{3}\right)$. The new volume of water after the cooked grains were added to the measuring cylinder was noted as $\left(\mathrm{V}_{4}\right)$. The volume of cooked grains was obtained by subtracting the Volume of water containing cooked-rice grains from the initial volume of water contained in the measuring cylinder (Equation 2).

$$
V_{2}(m l)=V_{4}-V_{3}
$$

Where, $\mathrm{V}_{2}$ = volume of cooked rice grain $(\mathrm{ml})$, $\mathrm{V}_{4}=$ New volume of water after the cooked grains were added to the measuring cylinder $(\mathrm{ml})$ $\mathrm{V}_{3}=$ volume of water used in determining volume of cooked grain (ml).

\section{Density of cooked rice grain (DCG)}

Density of a cooked rice grain was obtained by dividing one-thousand grain weight of cooked rice

\begin{tabular}{l|l|l|l} 
IJFS | October 2020 | Volume 9 & pages 319-331
\end{tabular} 
grain with its volume (Equation 3)

$$
\operatorname{Density}(g / m l)=\frac{W_{2}}{V_{2}}
$$

\section{Determination of minimum and optimum cooking time}

The minimum and optimum cooking times were determined according to the method described by Odenigbo et al. (2014).

\section{Quantity of water absorbed}

Quantity of water $\mathrm{V}_{6}(\mathrm{ml})$ absorbed by rice samples was determined as described by Gariboldi (1979). The remaining distilled water, after the rice reached its optimum cooking time, was measured in a volumetric flask and its volume recorded $\left(\mathrm{V}_{5}\right)$. Quantity of water absorbed was obtained by subtracting the volume of remaining distilled water from the initial volume of water used in cooking rice samples (Equation 4).

$$
V_{6}(m l)=V_{1}-V_{5}
$$

Where, $\mathrm{V}_{6}=$ volume of water absorbed by rice sample $(\mathrm{ml})$;

$\mathrm{V}_{1}=$ initial volume of water used in cooking rice sample $(\mathrm{ml})$

$\mathrm{V}_{5}=$ volume of water remaining after cooking rice $(\mathrm{ml})$

\section{Volume expansion ratio (VER)}

Volume expansion ratio was determined according to the method described by Gariboldi (1979). The volume expansion ratio $\left(\mathrm{V}_{8}\right)$ was calculated using Equation (5)

$$
V_{8}=\frac{V_{2}}{V_{7}}
$$

Where, $\mathrm{V}_{2}=$ volume of cooked rice $(\mathrm{ml})$ and $\mathrm{V}_{7}=$ volume of raw rice $(\mathrm{ml})$.

\section{Weight increase (WI)}

The increase in weight of rice samples was obtained as described by Gariboldi (1979). The cooked rice grains were removed from the water bath and allowed to drain off excess water. One hundred (100) cooked rice grains were weighed $\left(\mathrm{W}_{2}\right)$ and multiplied by 10 . The increase in weight was obtained by subtracting the weight of cooked rice grains from the uncooked rice grains W1 (Equation 6).

$$
W_{8}(g)=W_{2}-W_{1}
$$

Where, $\mathrm{W}_{3}=$ weight increase of cooked rice $(\mathrm{g})$; $\mathrm{W}_{2}=$ weight of cooked rice $(\mathrm{g})$

$\mathrm{W}_{1}=$ weight of raw rice $(\mathrm{g})$

\section{Elongation ratio (ER)}

Elongation ratio of rice grain samples was determined according to the method of Odenigbo et al. (2014). Ten optimum cooked grains of each sample were measured using a digital calliper (0.1-100mm A\&D Company Limited). Average length of the cooked grains $\left(\mathrm{L}_{2}\right)$ was divided by average length of 10 uncooked grains sample $\left(\mathrm{L}_{I}\right)$ for each variety and Equation (7) used to evaluate their Elongation ratio.

$$
E R=\frac{L_{2}}{L_{1}}
$$

\section{Water uptake ratio (WUR)}

Water Uptake Ratio was determined according to the method described by Bida (2013). The optimum cooked grains were strained and placed on filter paper to remove excess water and weighed. The WUR was determined as shown in equation 8

$$
W U R=\frac{W_{2}}{W_{1}}
$$

\section{Degree of agglutination (solid loss in water)}

The Resistance of kernels to become sticky on boiling (degree of agglutination) was determined according to the method described by Gariboldi (1979). All the water used for boiling rice was drained off and afterwards evaporated. The amount of solid matter lost while cooking rice samples was obtained and weighed. The weight obtained is the degree of agglutination expressed in grams $\mathrm{W}_{3}$. 


\section{$2.3 \quad$ Functional properties}

\section{Gel consistency (GC) determination}

Gel Consistency (GC) of the rice samples was determined according to the method of Cagampang, Perez and Juliano (1973). $100 \mathrm{mg}$ rice flour of $12 \%$ moisture was placed in $13 \times 100 \mathrm{~mm}$ culture tubes. The powder was wet with $0.2 \mathrm{ml} 95 \%$ ethanol containing $0.025 \%$ thymol blue. The tube was shaken and $2.0 \mathrm{ml}$ of $0.2 \mathrm{~N} \mathrm{KOH}$ added immediately and the mixture dispersed. The tubes were covered with glass marbles and placed for 8 minutes in a boiling water bath. Afterwards, the samples were removed and kept at room temperature for 5 minutes, and then cooled in ice cold water for 15 minutes. The tubes were removed afterwards from ice water and laid horizontally over a ruled paper graduated in millimetres and the length of the gel from the bottom of the test tube was measured after 30-60 minutes. The rice was classified based on these categories: Soft $=61-100 \mathrm{~mm}$, Medium $=41-60$ $\mathrm{mm}, \mathrm{Hard}=26-40 \mathrm{~mm}$

\section{Amylose content determination}

Amylose Content (AC) was determined according to the method of Juliano (1971). 100mg of rice flour was poured into a $100 \mathrm{ml}$ volumetric flask. $1 \mathrm{ml}$ of $95 \%$ ethanol and $9 \mathrm{ml}$ of $1 \mathrm{~N}$ $\mathrm{NaOH}$ was added to the rice flour and the mixture heated for 10 minutes in a boiling water bath. After heating, the mixture was cooled and made up to $100 \mathrm{ml}$ volume with distilled water. $5 \mathrm{ml}$ of the $100 \mathrm{ml}$ solution was taken and put into another $100 \mathrm{ml}$ volumetric flask. $1 \mathrm{ml}$ of $1 \mathrm{~N}$ acetic acid was added and $2 \mathrm{ml}$ Iodine-potassium iodide solution added subsequently. The volume of the mixture was made up to $100 \mathrm{ml}$ with distilled water. The sample was shaken and allowed to stand for 20 minutes and the per cent Transmittance determined at $620 \mathrm{~nm}$ using a colorimeter. Amylose content of the samples was determined in reference to a standard curve (graph) and expressed on percent basis.

$$
\text { Amylose }(\%)=[\text { Amylose }]_{S t d} \cdot \frac{A_{\text {sample }}}{A_{\text {std }}}
$$

where $[\text { Amylose }]_{S t d}$ is the Amylose content of standard in

$$
\text { Amylopectin(\%) }=100-\% \text { Amylose }
$$

Based on amylose content, milled rice is classified in "amylose groups", as follows: waxy (1$2 \%$ amylose), very low amylose content (2-9\% amylose), low amylose content (10-20\% amylose), intermediate amylose content (20-25\% amylose) and high amylose content (25-33\% amylose) (Bida, 2013).

\subsection{Statistical Analysis}

The study adopted a completely randomized design (CRD). The data generated were subjected to one way analysis of variance (ANOVA) using SPSS version 20.0. Means were separated using Duncan's Multiple Range Test (DMRT) and significance was accepted at 0.05 level of probability (Akande, Onyegbula, Salawu, K Oladipo \& Adetunji, 2017).

\section{Results and Discussion}

\subsection{Cooked grain dimensions}

Table 1 shows the length, width, thickness and length-width ratio of raw and cooked domestic rice varieties marketed in South-East Nigeria. There was a significant $(\mathrm{p}<0.05)$ increase in the length, width and thickness of all the rice varieties when cooked. All of the raw medium and long grain rice varieties became extra-long grains when cooked as described by the FAO (Foot note Table 1). Akpujie had the highest cooked grain length $(10.19 \mathrm{~mm})$ compared to Ip2 an imported rice variety $(9.95 \mathrm{~mm})$. Ip1 had the highest length-width ratio $(3.52 \mathrm{~mm})$ compared to Abakiliki Mas a local rice variety $(3.20 \mathrm{~mm})$. Table 2 shows the weight, volume and density of raw and cooked domestic rice varieties sold in South-East Nigeria. There was a significant (p $<0.05$ ) increase in the volume and weight of all the rice grains when cooked. There was an increase of more than $25 \mathrm{~g}$ in weight of all the rice varieties when cooked. Geshua had the highest cooked grain weight $(68.67 \mathrm{~g})$ compared to Ip3 $(59.33 \mathrm{~g})$. FARO 40 had the highest cooked grain

IJFS | October 2020| Volume 9 | pages 319-331 
324 | Azuka et al.

Table 1: Length, Width, Thickness and Length-width ratio of Raw and Cooked Domestic Rice Varieties Sold in the South-East Nigeria

\begin{tabular}{|c|c|c|c|c|c|c|c|c|}
\hline Rice variety & LRG (mm) & LCG (mm) & WRG $(\mathrm{mm})$ & WCG (mm) & TRG(mm) & TCG $(\mathrm{mm})$ & L/WRG & L/WCG \\
\hline \multicolumn{9}{|c|}{ Imported Rice Variety } \\
\hline Ip1 & $7.19^{a b} \pm 0.35$ & $9.48^{b c} \pm 0.64$ & $2.03^{i j} \pm 0.15$ & $2.71^{g} \pm 0.19$ & $1.69^{e} \pm 0.12$ & $2.33^{e f} \pm 0.25$ & $3.57^{a} \pm 0.34$ & $3.52^{a} \pm 0.19$ \\
\hline Ip2 & $7.07^{a b c} \pm 0.27$ & $9.95^{a b} \pm 0.57$ & $2.08^{h i j} \pm 0.12$ & $2.87^{f g} \pm 0.16$ & $1.77^{a b c d e} \pm 0.11$ & $2.30^{f} \pm 0.09$ & $3.40^{a b} \pm 0.19$ & $3.47^{a} \pm 0.27$ \\
\hline Ip3 & $6.11^{i j} \pm 0.47$ & $9.02^{\text {cde }} \pm 0.42$ & $2.00^{j} \pm 0.12$ & $3.01^{d e f} \pm 0.26$ & $1.68^{e} \pm 0.11$ & $2.45^{\text {def }} \pm 0.18$ & $3.08^{\text {cde }} \pm 0.20$ & $3.03^{b c d e} \pm 0.33$ \\
\hline \multicolumn{9}{|l|}{ Enugu State } \\
\hline Faro 44 & $6.86^{\text {bcdef }} \pm 0.31$ & $9.20^{c d} \pm 0.43$ & $2.24^{\text {defgh }} \pm 0.13$ & $3.13^{\text {cdef }} \pm 0.22$ & $1.83^{a b c} \pm 0.12$ & $2.44^{\text {def }} \pm 0.18$ & $3.08^{\text {cde }} \pm 0.20$ & $2.95^{\text {bcdefg }} \pm 0.17$ \\
\hline Fadama & $6.12^{i j} \pm 0.56$ & $8.09^{g h} \pm 0.39$ & $2.21^{e f g h} \pm 0.20$ & $2.94^{e f g} \pm 0.18$ & $1.86^{a b} \pm 0.16$ & $2.46^{\text {def }} \pm 0.21$ & $2.79^{f g h} \pm 0.21$ & $2.78^{e f g h} \pm 0.19$ \\
\hline Fortin 16 & $6.41^{g h i j} \pm 0.27$ & $8.35^{f g h} \pm 0.98$ & $2.26^{\text {cdef } g} \pm 0.17$ & $2.90^{f g} \pm 0.35$ & $1.88^{a} \pm 0.11$ & $2.42^{\text {def }} \pm 0.16$ & $2.84^{e f g} \pm 0.27$ & $2.90^{\text {cdefg }} \pm 0.38$ \\
\hline Fortin 16 (old variety) & $6.45^{\text {fghij }} \pm 0.54$ & $8.60^{\text {defg }} \pm 0.26$ & $2.19^{\text {efghi }} \pm 0.21$ & $2.95^{e f g} \pm 0.36$ & $1.85^{a b} \pm 0.14$ & $2.31^{f} \pm 0.23$ & $2.99^{\text {def } g} \pm 0.43$ & $2.98^{\text {bcdef }} \pm 0.41$ \\
\hline \multicolumn{9}{|c|}{ Anambra State } \\
\hline Omor-Mas & $6.25^{h i j} \pm 0.30$ & $8.66^{\text {defg }} \pm 0.60$ & $2.29^{\text {cdef }} \pm 0.09$ & $3.25^{b c d} \pm 0.31$ & $1.73^{b c d e} \pm 0.08$ & $2.62^{b c d} \pm 0.23$ & $2.74^{g h} \pm 0.10$ & $2.69^{g h} \pm 0.30$ \\
\hline R-Bus & $6.60^{\text {defgh }} \pm 0.51$ & $9.48^{b c} \pm 0.90$ & $2.17^{\text {efghij }} \pm 0.22$ & $3.10^{\text {cdef }} \pm 0.37$ & $1.70^{d e} \pm 0.16$ & $2.43^{\text {def }} \pm 0.24$ & $3.07^{d e} \pm 0.35$ & $3.07^{b c d} \pm 0.21$ \\
\hline Faro 40 & $6.55^{e f g h i} \pm 0.41$ & $8.97^{\text {cdef }} \pm 0.57$ & $2.17^{e f g h i j} \pm 0.12$ & $3.01^{\text {def }} \pm 0.17$ & $1.82^{a b c d} \pm 0.06$ & $2.52^{\text {cdef }} \pm 0.15$ & $3.03^{\text {def }} \pm 0.19$ & $2.98^{\text {bcdef }} \pm 0.19$ \\
\hline Igboukwu rice & $6.07^{j k} \pm 0.44$ & $8.46^{e f g h} \pm 0.61$ & $2.40^{b c d} \pm 0.13$ & $3.25^{b c d} \pm 0.15$ & $1.82^{a b c d} \pm 0.10$ & $2.63^{b c d} \pm 0.21$ & $2.54^{h i} \pm 0.22$ & $2.60^{h} \pm 0.22$ \\
\hline Aguleri rice & $6.33^{g h i j} \pm 0.56$ & $8.62^{d e f g} \pm 0.47$ & $2.57^{a} \pm 0.13$ & $3.40^{b} \pm 0.25$ & $1.86^{a b} \pm 0.10$ & $2.59^{b c d} \pm 0.19$ & $2.45^{i} \pm 0.22$ & $2.53^{h i} \pm 0.19$ \\
\hline Taraba rice & $6.71^{\text {cdefg }} \pm 0.36$ & $8.87^{\text {cdef }} \pm 0.87$ & $2.14^{f g h i j} \pm 0.21$ & $3.21^{b c d e} \pm 0.30$ & $1.68^{e} \pm 0.15$ & $2.53^{\text {bcdef }} \pm 0.25$ & $3.17^{b c d} \pm 0.36$ & $2.79^{\text {defgh }} \pm 0.31$ \\
\hline B-G & $6.50^{e f g h i j} \pm 0.39$ & $8.96^{\text {cdef }} \pm 0.44$ & $2.41^{b c} \pm 0.24$ & $3.31^{b c} \pm 0.31$ & $1.84^{a b c} \pm 0.11$ & $2.73^{a b c} \pm 0.21$ & $2.73^{g h} \pm 0.26$ & $2.73^{f g h} \pm 0.32$ \\
\hline \multicolumn{9}{|l|}{ Ebonyi State } \\
\hline Akpujie & $7.47^{a} \pm 0.76$ & $10.19^{a} \pm 0.62$ & $2.33^{b c d e} \pm 0.17$ & $3.45^{b} \pm 0.25$ & $1.78^{\text {abcde }} \pm 0.10$ & $2.91^{a} \pm 0.26$ & $3.22^{b c d} \pm 0.24$ & $2.95^{\text {bcdefg }} \pm 0.17$ \\
\hline Kpurukpuru & $5.69^{k L} \pm 0.15$ & $7.89^{h} \pm 0.72$ & $2.47^{a b} \pm 0.12$ & $3.42^{b} \pm 0.37$ & $1.83^{a b c} \pm 0.11$ & $2.76^{a b} \pm 0.16$ & $2.30^{i j} \pm 0.14$ & $2.34^{i j} \pm 0.30$ \\
\hline Afikpo-Mas & $6.72^{\text {cdefg }} \pm 0.35$ & $9.23^{c d} \pm 0.43$ & $2.11^{g h i j} \pm 0.13$ & $2.99^{\text {def }} \pm 0.22$ & $1.70^{d e} \pm 0.22$ & $2.55^{b c d e} \pm 0.33$ & $3.20^{b c d} \pm 0.21$ & $3.12^{b c} \pm 0.33$ \\
\hline Abakiliki Mas & $7.00^{b c d} \pm 0.30$ & $9.11^{c d} \pm 0.51$ & $2.10^{g h i j} \pm 0.12$ & $2.87^{f g} \pm 0.26$ & $1.66^{e} \pm 0.13$ & $2.49^{\text {def }} \pm 0.23$ & $3.35^{a b c} \pm 0.29$ & $3.20^{b} \pm 0.29$ \\
\hline R-8 & $6.63^{\text {defgh }} \pm 0.38$ & $9.22^{c d} \pm 0.35$ & $2.22^{e f g h} \pm 0.18$ & $3.06^{\text {cdef }} \pm 0.15$ & $1.72^{\text {cde }} \pm 0.08$ & $2.59^{b c d} \pm 0.16$ & $3.02^{\text {def }} \pm 0.40$ & $3.01^{\text {bcdef }} \pm 0.19$ \\
\hline 306 & $6.93^{b c d e} \pm 0.61$ & $8.72^{d e f} \pm 0.84$ & $2.18^{\text {efghi}} \pm 0.12$ & $3.13^{\text {cdef }} \pm 0.19$ & $1.77^{\text {abcde }} \pm 0.07$ & $2.63^{b c d} \pm 0.36$ & $3.18^{b c d} \pm 0.28$ & $2.79^{\text {defgh }} \pm 0.32$ \\
\hline Geshua & $5.55^{L} \pm 0.31$ & $8.09^{g h} \pm 0.47$ & $2.57^{a} \pm 0.27$ & $3.70^{a} \pm 0.30$ & $1.74^{b c d e} \pm 0.13$ & $2.74^{a b c} \pm 0.29$ & $2.18^{j} \pm 0.19$ & $2.21^{j} \pm 0.17$ \\
\hline Mean & $6.53 \pm 0.62$ & $8.91 \pm 0.81$ & $2.24 \pm 0.22$ & $3.13 \pm 0.34$ & $1.77 \pm 0.14$ & $2.54 \pm 0.26$ & $2.95 \pm 0.44$ & $2.89 \pm 0.40$ \\
\hline LSD0.05 & 0.38 & 0.54 & 0.15 & 0.23 & 0.11 & 0.20 & 0.24 & 0.24 \\
\hline CV (\%) & 6.6 & 6.9 & 7.4 & 8.5 & 6.9 & 8.8 & 9.1 & 9.4 \\
\hline
\end{tabular}

Extra-long grain rice $=7.00 \mathrm{~mm}$ and above, Long grain rice $=6.00$ to $6.99 \mathrm{~mm}$, medium grain rice $=5.00$ to $5.99 \mathrm{~mm}$, short grain rice $=$ less than $5.00 \mathrm{~mm}$. $\mathrm{LRG}=$ Length of raw grain, $\mathrm{LCG}=$ Length of cooked grain $\mathrm{WRG}=$ Width of raw grain, WCG $=$ Width of cooked grain, TRG= thickness of raw grain, $\mathrm{TCG}=$ thickness of cooked grain, $\mathrm{L} / \mathrm{WRG}=$ Length-width ratio of raw grain, $\mathrm{L} / \mathrm{WCG}=$ Length-width ratio of cooked grain

volume $(80.00 \mathrm{ml})$ compared to $\mathrm{Ip} 1(73.33 \mathrm{ml})$ while Ip3 had the highest cooked grain density $\left(1.93 \mathrm{~g} / \mathrm{ml}^{3}\right)$. The cooked grains were less dense than the raw grains as a result of the increase in volume of the rice grains when cooked (expansion of the starch granules) and a non-variation or change in the molecular mass of the cooked grains.

\subsection{Other cooking properties of domestic rice varieties}

Table 3 shows other cooking properties of domestic rice varieties sold in South-East Nigeria. Ip3 had the highest ER (1.50) compared to a local rice variety (1.46) though there was no significant $(\mathrm{p}>0.05)$ difference between them. The elongation ratios of all the local rice varieties were more than 1.26 of its raw grain length when cooked. The values of ER (1.27-1.50) were within those (1.08-3.20) reported by Oko, Ubi and Nahemiah (2012) for selected local and newly in- troduced rice varieties in Ebonyi State, Nigeria. Thomas et al. (2013) reported ER values of 1.371.77 for six different rice cultivars in Penang, Malaysia. Yadav, Khatkar and Yadav (2007) had earlier reported ER values of 1.52-1.89 for some Indian rice (oryza sativa L.) cultivars which were similar to those (1.29-1.74) reported by Singh, Kaur, Sodhi and Sekhon (2005) for 23 milled varieties of Indian rice. Geshua had the highest weight increase (49.67 g) compared to an imported rice variety $(41.33 \mathrm{~g})$.

Omor-mas and R-Bus had the highest VER (6.00) compared to an imported rice variety (5.00). There was an expansion ratio of more than 3.00 for the rice varieties' raw grain volume (3.03-6.00) when cooked (Table 3) except for Fadama (2.0). These rice varieties with high VER would produce rice with higher volume than those with less VER, of the same quantity, when cooked and this is desirable. According to Akaeze (2010), imported rice swelling capacity is mostly preferred by restaurants and fast food 
Cooking properties of parboiled milled domestic rice $\mid 325$

Table 2: Weight, Volume and Density of Raw and Cooked Domestic Rice Varieties Sold in South-East Nigeria

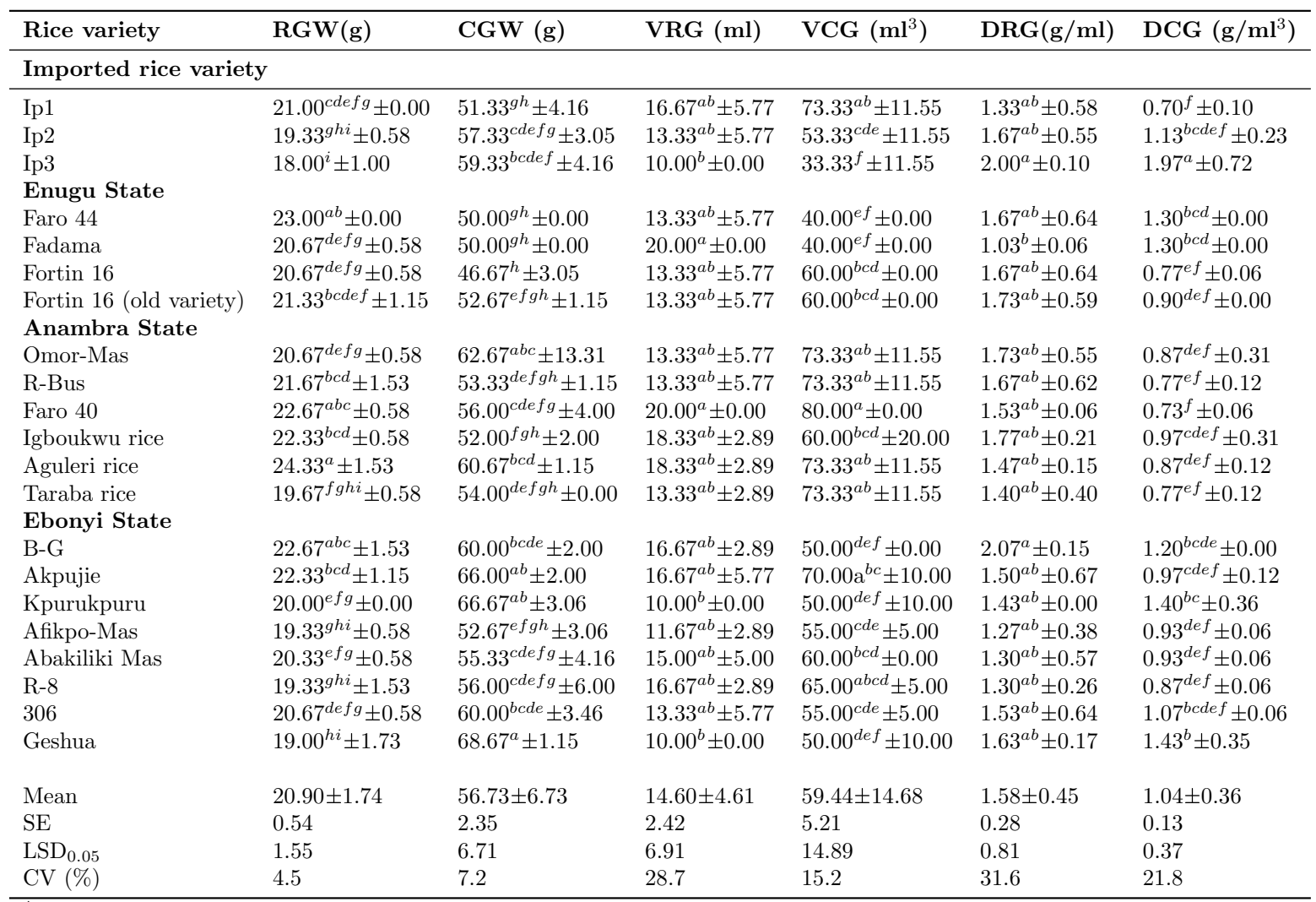

* Values are means \pm standard deviation of triplicate determination. Means in the same column carrying similar superscript are not significantly $(\mathrm{P}>0.05)$ different

$\mathrm{RGW}=$ Raw grain weight, $\mathrm{CGW}=$ cooked grain weight, $\mathrm{VRG}=$ volume of raw grain $\mathrm{VCG}=$ volume of cooked grain,

$\mathrm{DRG}=$ density of raw grain $\mathrm{DCG}=$ density of cooked grain

outlets, which is one of the reasons why imported rice consumption in Nigeria has expanded at the expense of local rice market development. It is clear that the above statement is not absolutely correct as Omor-Mas and R-Bus, which are local rice varieties, had the highest volume expansion ratio among all the rice varieties. Food vendors should use rice varieties with high VER in order to increase profit from sales.

From Table 4, the water uptake ratio of Geshua (3.63) was higher compared to Ip3 an imported rice variety (3.30). WUR is a measure of the rate at which the rice grains take up water and increase in weight. WUR had a high positive correlation (0.95) with weight increase. Geshua and Kpurukpuru had the highest water uptake ratio of 3.63 and 3.33 respectively, and thus had higher weight. Geshua which had the least raw grain weight (Table 1) among the local rice varieties had the highest cooked grain weight of 68.67 because of its WUR. Grains with high WUR are desirable as they will cause increase in weight and increased satiety when consumed.

Kpurukpuru and Geshua had the highest optimum cooking time (OCT) of 45.33 and 40.00 minutes respectively compared to the imported rice varieties (22.67-31.33 mins). However, a significant percentage $(33.33 \%)$ of the local rice varieties had a lower OCT (17.00-21.33 mins) than the imported rice varieties while a large percentage $(83.33 \%)$ of the local rice varieties were within the range of OCT (17.00-29.33 mins) 
326 | Azuka et al.

Table 3: Some Cooking Properties of Domestic Rice Varieties Sold in South-East Nigeria

\begin{tabular}{llll}
\hline Rice variety & ER & WI $(\mathrm{g})$ & VER \\
\hline Imported rice variety & & & \\
Ip1 & $1.32^{b c d} \pm 0.13$ & $30.33^{\text {ghij }} \pm 4.16$ & $5.00^{a b} \pm 2.65$ \\
Ip2 & $1.41^{a b c d} \pm 0.07$ & $38.00^{\text {cdefg }} \pm 2.65$ & $4.33^{a b c} \pm 1.53$ \\
Ip3 & $1.50^{a} \pm 0.17$ & $41.33^{\text {bcde }} \pm 5.13$ & $3.33^{a b c} \pm 1.15$ \\
Enugu State & & & \\
Faro 44 & $1.35^{b c d} \pm 0.11$ & $27.00^{i j} \pm 0.00$ & $3.33^{a b c} \pm 1.15$ \\
Fadama & $1.33^{b c d} \pm 0.14$ & $29.33^{\text {hij }} \pm 0.58$ & $2.0^{c} \pm 0.00$ \\
Fortin 16 & $1.30^{d} \pm 0.13$ & $26.00^{j} \pm 2.65$ & $5.00^{a b} \pm 1.73$ \\
Fortin 16 (old variety) & $1.34^{b c d} \pm 0.10$ & $31.33^{\text {fghij }} \pm 1.15$ & $5.00^{a b} \pm 1.73$ \\
Anambra State & & & \\
Omor-Mas & $1.40^{a b c d} \pm 0.12$ & $42.00^{b c d} \pm 13.74$ & $6.00^{a} \pm 2.00$ \\
R-Bus & $1.46^{a b} \pm 0.17$ & $31.67^{\text {fghij }} \pm 2.08$ & $6.00^{a} \pm 2.00$ \\
Faro 40 & $1.38^{a b c d} \pm 0.10$ & $33.33^{\text {efghij }} \pm 4.04$ & $4.00^{a b c} \pm 0.00$ \\
Igboukwu rice & $1.39^{a b c d} \pm 0.15$ & $29.67^{\text {ghij }} \pm 2.08$ & $3.23^{a b c} \pm 0.68$ \\
Aguleri rice & $1.38^{a b c d} \pm 0.18$ & $36.33^{\text {cdefgh }} \pm 2.08$ & $4.00^{a b c} \pm 0.00$ \\
Taraba rice & $1.32^{b c d} \pm 0.15$ & $34.33^{\text {defghi }} \pm 0.58$ & $5.77^{a b} \pm 2.04$ \\
B-G & $1.37^{a b c d} \pm 0.13$ & $37.33^{\text {cdefgh }} \pm 2.08$ & $3.03^{b c} \pm 0.46$ \\
Ebonyi State & & & \\
Akpujie & $1.38^{a b c d} \pm 0.18$ & $43.67^{a b} \pm 3.06$ & $4.50^{a b c} \pm 1.32$ \\
Kpurukpuru & $1.40^{a b c d} \pm 0.16$ & $46.67^{a b} \pm 3.06$ & $5.00^{a b} \pm 1.00$ \\
Afikpo-Mas & $1.38^{a b c d} \pm 0.10$ & $33.33^{\text {efghij }} \pm 3.21$ & $4.93^{a b} \pm 1.44$ \\
Abakiliki Mas & $1.31^{c d} \pm 0.06$ & $35.00^{\text {defghi }} \pm 3.61$ & $4.33^{a b c} \pm 1.53$ \\
R-8 & $1.39^{a b c d} \pm 0.10$ & $36.67^{\text {cdefgh }} \pm 6.66$ & $3.93^{a b c} \pm 0.40$ \\
306 & $1.27^{d} \pm 0.15$ & $39.33^{\text {bcdef }} \pm 3.79$ & $4.60^{a b c} \pm 1.64$ \\
Geshua & $1.45^{a b c} \pm 0.12$ & $49.67^{a} \pm 1.73$ & $5.00^{a b} \pm 1.00$ \\
Mean & & & \\
SE & $1.37 \pm 0.14$ & $35.83 \pm 7.14$ & $4.40 \pm 1.54$ \\
LSD0.05 & 0.04 & 2.44 & 0.83 \\
CV (\%) & 9.12 & 6.98 & 2.37 \\
\hline Vab & 11.8 & 32.7 \\
\hline
\end{tabular}

* Values are means \pm standard deviation of triplicate determination.

Means in the same column carrying similar superscript are not significantly $(\mathrm{P}>0.05)$ different. $\mathrm{ER}=$ Elongation ratio, $\mathrm{WI}=$ weight increase,

$\mathrm{VER}=$ volume expansion ratio 
Cooking properties of parboiled milled domestic rice $\mid 327$

Table 4: Some Cooking Properties of Domestic Rice Varieties Sold in South-East Nigeria (Continued)

\begin{tabular}{|c|c|c|c|c|c|}
\hline Rice variety & WUR & MCT (mins) & OCT (mins) & SLIW (g) & VWA (ml) \\
\hline \multicolumn{6}{|l|}{ Imported rice variety } \\
\hline Ip1 & $2.47^{\text {defg }} \pm 0.21$ & $20.67^{f g h i} \pm 3.79$ & $22.67^{f g h i} \pm 3.79$ & $0.03^{b c} \pm 0.06$ & $26.33^{a b} \pm 1.15$ \\
\hline Ip2 & $2.97^{b c d} \pm 0.15$ & $20.00^{f g h i} \pm 7.81$ & $22.00^{f g h i} \pm 7.81$ & $0.17^{a b c} \pm 0.12$ & $26.00^{a b} \pm 4.00$ \\
\hline Ip3 & $3.30^{a b} \pm 0.46$ & $29.33^{c} \pm 0.58$ & $31.33^{c} \pm 0.58$ & $0.20^{a b} \pm 0.20$ & $27.67^{a} \pm 2.52$ \\
\hline \multicolumn{6}{|l|}{ Enugu state } \\
\hline Faro 44 & $2.20^{g} \pm 0.00$ & $20.67^{f g h i} \pm 3.21$ & $22.67^{f g h i} \pm 3.21$ & $0.10^{a b c} \pm 0.10$ & $25.00^{a b c d} \pm 3.46$ \\
\hline Fadama & $2.43^{e f g} \pm 0.06$ & $15.00^{j} \pm 0.00$ & $17.00^{j} \pm 0.00$ & $0.17^{a b c} \pm 0.15$ & $24.67^{a b c d e} \pm 2.08$ \\
\hline Fortin 16 & $2.27^{f g} \pm 0.12$ & $17.67^{\text {ghij }} \pm 2.08$ & $19.67^{\text {ghij }} \pm 2.08$ & $0.07^{b c} \pm 0.06$ & $24.33^{a b c d e} \pm 2.52$ \\
\hline Fortin 16 (old variety) & $2.50^{\text {defg }} \pm 0.10$ & $23.67^{\text {def }} \pm 0.58$ & $25.67^{\text {def }} \pm 0.58$ & $0.10^{a b c} \pm 0.00$ & $17.67^{h} \pm 2.31$ \\
\hline \multicolumn{6}{|l|}{ Anambra state } \\
\hline Omor-Mas & $3.03^{b c} \pm 0.70$ & $36.67^{b} \pm 0.58$ & $38.67^{b} \pm 0.58$ & $0.10^{a b c} \pm 0.00$ & $22.00^{b c d e f g h} \pm 2.65$ \\
\hline R-Bus & $2.47^{\text {defg }} \pm 0.21$ & $19.33^{\text {fghij }} \pm 4.04$ & $21.33^{\text {fghij }} \pm 4.04$ & $0.13^{a b c} \pm 0.15$ & $22.00^{b c d e f g h} \pm 3.61$ \\
\hline Faro 40 & $2.47^{\text {defg }} \pm 0.15$ & $17.00^{h i j} \pm 1.73$ & $19.00^{h i j} \pm 1.73$ & $0.13^{a b c} \pm 0.06$ & $23.67^{a b c d e} \pm 0.58$ \\
\hline Igboukwu rice & $2.37^{f g} \pm 0.12$ & $19.33^{\text {fghij }} \pm 0.58$ & $21.33^{f g h i j} \pm 0.58$ & $0.07^{b c} \pm 0.12$ & $22.67^{b c d e f g} \pm 2.08$ \\
\hline Aguleri rice & $2.50^{d e f g} \pm 0.17$ & $26.33^{c d e} \pm 0.58$ & $28.33^{c d e} \pm 0.58$ & $0.07^{b c} \pm 0.06$ & $25.33^{a b c} \pm 2.08$ \\
\hline Taraba rice & $2.73^{\text {cdef }} \pm 0.06$ & $27.33^{c d} \pm 0.58$ & $29.33^{c d} \pm 0.58$ & $0.07^{b c} \pm 0.06$ & $23.00^{\text {abcdef }} \pm 3.00$ \\
\hline $\mathrm{B}-\mathrm{G}$ & $2.67^{\text {cdefg }} \pm 0.21$ & $26.00^{\text {cde }} \pm 3.61$ & $28.00^{\text {cde }} \pm 3.61$ & $0.27^{a} \pm 0.06$ & $18.67^{f g h} \pm 1.53$ \\
\hline \multicolumn{6}{|l|}{ Ebonyi state } \\
\hline Akpujie & $2.97^{b c d} \pm 0.21$ & $21.67^{\text {efgh }} \pm 0.58$ & $23.67^{e f g h} \pm 0.58$ & $0.07^{b c} \pm 0.06$ & $18.67^{f g h} \pm 2.08$ \\
\hline Kpurukpuru & $3.33^{a b} \pm 0.15$ & $43.33^{a} \pm 0.58$ & $45.33^{a} \pm 0.58$ & $0.13^{a b c} \pm 0.12$ & $20.00^{e f g h} \pm 3.46$ \\
\hline Afikpo-Mas & $2.70^{\text {cdefg }} \pm 0.17$ & $16.33^{i j} \pm 2.52$ & $18.33^{i j} \pm 2.52$ & $0.13^{a b c} \pm 0.06$ & $22.67^{\text {bcdefg }} \pm 0.58$ \\
\hline Abakiliki Mas & $2.73^{\text {cdef }} \pm 0.15$ & $20.00^{f g h i} \pm 1.73$ & $22.00^{f g h i} \pm 1.73$ & $0.13^{a b c} \pm 0.06$ & $20.33^{\text {defgh }} \pm 2.52$ \\
\hline $\mathrm{R}-8$ & $2.90^{b c d e} \pm 0.44$ & $22.67^{\text {defg }} \pm 2.89$ & $24.67^{\text {defg }} \pm 2.89$ & $0.00^{c} \pm 0.00$ & $21.00^{c d e f g h} \pm 2.65$ \\
\hline 306 & $2.93^{b c d e} \pm 0.21$ & $26.33^{c d e} \pm 0.58$ & $28.33^{c d e} \pm 0.58$ & $0.07^{b c} \pm 0.06$ & $18.00^{g h} \pm 1.73$ \\
\hline Geshua & $3.63^{a} \pm 0.32$ & $38.00^{b} \pm 0.00$ & $40.00^{b} \pm 0.00$ & $0.07^{b c} \pm 0.06$ & $17.67^{h} \pm 2.52$ \\
\hline Mean & $2.74 \pm 0.43$ & $24.16 \pm 7.66$ & $26.16 \pm 7.66$ & $0.11 \pm 0.10$ & $22.25 \pm 3.64$ \\
\hline $\mathrm{SE}$ & 0.15 & 1.53 & 1.53 & 0.05 & 1.45 \\
\hline LSD0.05 & 0.42 & 4.38 & 4.38 & 0.15 & 4.15 \\
\hline $\mathrm{CV}$ & 9.2 & 11.0 & 10.2 & 82.3 & 11.3 \\
\hline
\end{tabular}

* Values are means \pm standard deviation of triplicate determination. Means in the same column carrying similar superscript are not significantly $(\mathrm{P}>0.05)$ different.

$\mathrm{WUR}=$ water uptake ratio, $\mathrm{MCT}=$ minimum cooking time, $\mathrm{OCT}=$ optimum cooking time,

$\mathrm{SLIW}=$ solid loss in water, $\mathrm{VWA}=$ volume of water absorbed 
Table 5: Functional properties of Milled Domestic and Some Imported Rice Varieties Sold in South-East Nigeria

\begin{tabular}{|c|c|c|c|c|c|}
\hline Rice variety & Gelconsistency (mm) & $\begin{array}{l}\text { Gelconsistency } \\
\text { Behaviour }\end{array}$ & Amylose (\%) & Amylopectin (\%) & $\begin{array}{l}\text { Classification } \\
\text { based on Amyl- } \\
\text { ose Content }\end{array}$ \\
\hline \multicolumn{6}{|l|}{ Imported rice variety } \\
\hline Ip1 & $80.00^{a b c} \pm 10.00$ & Soft & $20.71^{g h} \pm 1.11$ & $79.29^{c d} \pm 1.11$ & Intermediate \\
\hline Ip2 & $73.50^{b c d} \pm 27.50$ & Soft & $23.14^{\text {def }} \pm 0.41$ & $76.86^{e f g} \pm 0.41$ & Intermediate \\
\hline Ip3 & $89.67^{a b} \pm 2.52$ & Soft & $21.63^{f g} \pm 1.54$ & $78.37^{d e} \pm 1.54$ & Intermediate \\
\hline \multicolumn{6}{|l|}{ Enugu state } \\
\hline FARO 44 & $88.00^{a b} \pm 10.00$ & Soft & $25.00^{a b c} \pm 0.80$ & $75.00^{h i j} \pm 0.80$ & High \\
\hline Fadama & $91.00^{a} \pm 0.00$ & Soft & $25.44^{a b} \pm 0.58$ & $74.56^{i j} \pm 0.58$ & High \\
\hline Fortin 16 & $97.00^{a} \pm 2.00$ & Soft & $24.20^{b c d} \pm 0.97$ & $75.80^{g h i} \pm 0.97$ & Intermediate \\
\hline Fortin 16 (old variety) & $89.50^{a b} \pm 0.50$ & Soft & $26.07^{f g} \pm 1.54$ & $73.93^{d e} \pm 1.54$ & High \\
\hline \multicolumn{6}{|c|}{ Anambra state } \\
\hline Omor-Mas & $91.67^{a} \pm 4.51$ & Soft & $26.08^{a} \pm 0.22$ & $73.92^{j} \pm 0.22$ & High \\
\hline R-Bus & $41.67^{e} \pm 16.50$ & Medium & $26.28^{a} \pm 1.05$ & $73.72^{j} \pm 1.05$ & intermediate \\
\hline FARO 40 & $97.00^{a} \pm 3.00$ & Soft & $22.43^{e f} \pm 0.63$ & $77.57^{e f} \pm 0.63$ & Intermediate \\
\hline Igboukwu rice & $94.25^{a} \pm 5.25$ & Soft & $20.11^{g h} \pm 0.94$ & $79.89^{c d} \pm 0.94$ & Low \\
\hline Aguleri rice & $93.67^{a} \pm 7.51$ & Soft & $19.20^{h i} \pm 0.38$ & $80.80^{b c} \pm 0.38$ & High \\
\hline Taraba rice & $93.00^{a} \pm 11.00$ & Soft & $26.04^{a} \pm 0.15$ & $73.96^{j} \pm 0.15$ & intermediate \\
\hline $\mathrm{B}-\mathrm{G}$ & $97.00^{a} \pm 3.00$ & Soft & $23.74^{g h} \pm 0.95$ & $76.26^{c d} \pm 0.95$ & Intermediate \\
\hline \multicolumn{6}{|l|}{ Ebonyi state } \\
\hline Akpujie & $69.27^{c d} \pm 9.25$ & Soft & $18.31^{\text {cde }} \pm 0.38$ & $81.69^{f g h} \pm 0.38$ & Low \\
\hline kpurukpuru & $63.67^{c d} \pm 2.52$ & Soft & $20.07^{i j} \pm 0.65$ & $80.72^{a b} \pm 0.65$ & Intermediate \\
\hline Afikpo-Mas & $92.83^{a} \pm 4.25$ & Soft & $25.30^{h i} \pm 0.63$ & $74.70^{b c} \pm 0.63$ & High \\
\hline Abakiliki Mas & $27.00^{e} \pm 2.00$ & Hard & $21.11^{e f} \pm 1.25$ & $78.89^{e f} \pm 1.25$ & Intermediate \\
\hline $\mathrm{R}-8$ & $33.67^{e} \pm 0.58$ & Hard & $27.21^{j} \pm 0.64$ & $79.29^{a} \pm 0.64$ & High \\
\hline 306 & $60.25^{d} \pm 4.25$ & Medium & $23.14^{g h} \pm 1.11$ & $76.86^{c d} \pm 1.11$ & Intermediate \\
\hline Geshua & $89.00^{a b} \pm 12.00$ & Soft & $25.47^{\text {def }} \pm 0.41$ & $74.53^{\text {efg }} \pm 0.41$ & High \\
\hline Mean & $78.70 \pm 22.60$ & & $22.26 \pm 2.71$ & $77.67 \pm 2.71$ & \\
\hline $\mathrm{SE}$ & 5.36 & & 0.50 & 0.50 & \\
\hline $\mathrm{LSD}_{0.05}$ & 15.32 & & 1.42 & 1.42 & \\
\hline $\mathrm{CV}$ & 11.8 & & 3.9 & 1.1 & \\
\hline
\end{tabular}

for imported rice varieties. There is a positive correlation (0.76) between OCT and WUR which shows that an increase in WUR will increase cooking time. A reduced cooking time is desirable because less energy and fuel would be consumed during cooking. The minimum cooking time for all the rice varieties ranged from 15-43.33 minutes and the optimum cooking time ranged from 17-45.33 minutes. This is within the ranges reported by Thomas et al. (2013) and Oko et al. (2012). The extra-long and long grains cooked for a shorter time (17-38.67 minutes) compared to the medium grains, Kpurukpuru and Ghesua, that cooked for 40 and 45.33 minutes respectively which were also of intermediate and high amylose content respectively. Nigeria's medium grain rice can be described as harder cooked rice than its extra-long and long grain rice. This is in contrast to domestic rice in the United States where their extra-long and long grain rice are harder cooked rice than the short and medium grain rice (Webb, 1972). Ip3 had the highest SLIW (0.20 g) compared to Fadama a local rice variety $(0.17 \mathrm{~g})$ though there was no significant $(p>0.05)$ difference amongst them. The SLIW of a large percentage (88.89 $\%)$ of the domestic rice varieties were minimal (0.03-0.13 \%). This result was similar to values 
reported by Yadav et al. (2007) for gruel solid losses of 0.025-0.52 g. Oko et al. (2012) also reported solids in cooking water of $0.01-0.95 \mathrm{~g}$ while Thomas et al. (2013) reported gruel solid loss of 0.03-0.06 g. The minimal values obtained for SLIW showed that there is less tendency of the grains to cling together when cooked.

The imported rice varieties had the highest VWA (26.00-27.67 ml) compared to a local rice (25.33 $\mathrm{ml}$ ). All the domestic rice samples imbibed less water when cooked than the imported rice varieties. This is desirable and showed that local rice varieties conserve water better than the imported rice varieties. From the results of the VWA (Table 4), using the optimum cooking time the quantity of water required to cook the grains to its optimum level can be deduced.

\subsection{Functional properties of domestic rice varieties}

The functional properties of domestic rice varieties sold in South-East Nigeria are shown in Table 5. Rice varieties of the same amylose content are usually differentiated by their degree of gel consistency. Those of high amylose-soft gel consistency are more-tender than those of high amylose-hard gel consistency. Large percentages $(77.78 \%)$ of the domestic rice varieties were of soft gel consistency $(63.67-97.00 \mathrm{~mm})$ and did not differ significantly $(\mathrm{p}>0.05)$ from the imported rice varieties $(89.67-73.50 \mathrm{~mm})$. Akpujie and Igboukwu-rice were of low amylose-soft gel consistency and will be suitable for use in baby foods and breakfast cereals because of their ability to produce relatively stable gels which tend to harden slowly during storage. Varieties with softer gel consistency are preferred for baby foods and cooked whole grains because of their higher degree of tenderness. Low amylose-soft gel consistency rice can also be used for popped rice and puffed rice as a result of its greater expansion volume (Juliano, 1971). In making fermented rice cakes, varieties with intermediate amylosesoft gel consistency are used such as Fortin 16, FARO 40, Taraba rice, B-G and Kpurukpuru because of their optimum volume expansion on steaming and their soft texture. R-Bus and 306 were of intermediate amylose-medium gel con- sistency and can find use in breakfast cereals as long as the water requirement is adjusted. Grains with high amylose-hard gel consistency find application in canned rice products and manufactured noodles. Abakiliki-Mas and R-8 should be used for canning purposes, rice-noodle manufacture and other high-temperature treatment processes because of their greater resistance to disintegration during cooking.

\section{Conclusion}

Akpujie had the highest cooked grain length $(10.19 \mathrm{~mm})$ among all the rice varieties. Geshua had the highest cooked grain width $(3.70 \mathrm{~mm})$, Akpujie had the highest cooked grain thickness $(2.91 \mathrm{~mm})$ and Ip1 had the highest cooked grain length-width ratio $(3.52 \mathrm{~mm})$. Geshua had the highest cooked grain weight $(68.67 \mathrm{~g})$. FARO 40 had the highest cooked grain volume $(80.00$ $\mathrm{ml}$ ), Ip3 had the highest cooked grain density $\left(1.93 \mathrm{~g} / \mathrm{ml}^{3}\right)$ and Ip3 had the highest ER (1.50). Omor-mas and R-Bus had the highest VER (6.00) and Geshua had the highest WUR (3.63). Kpurukpuru and Geshua had the highest OCT of 45.33 and 40.00 minutes respectively while $83.33 \%$ of the local rice varieties had OCT of 17.00-29.33 mins. Ip3 had the highest SLIW $(0.20 \mathrm{~g})$ while the imported rice varieties had the highest VWA (26.00-27.67 ml). Procurement and consumption of local rice varieties is highly encouraged for individuals, restaurants and fast food joints as a better increased weight, high volume expansion ratio, increased grain dimensions and conservation of water during cooking is obtained when compared with rice imported into Nigeria from Thailand and USA. The domestic rice varieties also have an elongation ratio comparable to imported rice, therefore, the statement that imported rice varieties had better cooking quality than the domestic rice varieties is not absolutely true. Most of the domestic rice varieties were of soft gel consistency but varied in amylose content, and therefore are excellent not only for consumption as cooked whole grain but in their diversification for making breakfast cereals, baby foods, puffed rice, popped rice, rice cakes, canned soups, dry mixes and rice noodles which will eliminate food bore-

IJFS | October 2020| Volume 9 | pages 319-331 
dom and stereotyped consumption. AbakilikiMas and R-8 should be used in making ricenoodles and subjected to other high-temperature processes which will limit over dependence on Durum wheat grain.

\section{References}

Abiona, O. E. (2011). Impact of nerica rice project on small scale rice farmer food accessibility. A case study ofon Obafemi Owode Local government Area, Ogun State, Nigeria (Master's thesis, Larenstein University Netherlands). Retrieved from http:// edepot.wur.nl/192615

Akaeze, H. O. (2010). Consumer preference for imported rice in nigeria-perceived quality differences or habit persistence? Michigan State University. Agricultural, Food and Resource Economics. Retrieved from https://books.google.com/books / about/ Consumer_Preference_for_Imported_Rice_ in.html?id=DZk1MQAACAAJ

Akande, S., Onyegbula, A., Salawu, R., K Oladipo, A. \& Adetunji, C. (2017). Effects of post-harvest handling on hydrogen cyanide content of cassava products obtained from ilorin-west urban markets, nigeria. African Journal of Food Science, 11, 362-368. doi:10.5897/AJFS2017.1537

Anonymous. (2009). The origin of rice. Basmati.ru. Retrieved from http://basmati . $\mathrm{ru} / \mathrm{en} /$ origin-of-rice

Bhonsle, S. J. \& Krishnan, S. (2010). Grain quality evaluation and organoleptic analysis of aromatic rice varieties of goa, india. $\mathrm{Ca}$ nadian Center of Science and Education (CCSE).

Bida, O. (2013). Rice quality: Rice post-harvest technology training program. Ministry of Agriculture, Animal Wealth and Natural Resources, General Administartion of Agriculture Rice Promotion Unit, Gezira State. Retrieved from https://www.jica.go. jp/project/english/sudan/001/materials / c8h0vm00007vrgs5-att/rice_quality_en.pdf

Cagampang, G. B., Perez, C. M. \& Juliano, B. (1973). A gel consistency test for eating quality of rice. Journal of the Science of Food and Agriculture, 24, 1589-1594. doi:10.1002/jsfa.2740241214

Danbaba, N., Nkama, I., Badau, M. H., Ukwungwu, M. N., Maji, A. T., Abo, M. E., ... Oko, A. O. (2014). Optimization of rice parboiling process for optimum head rice yield: A response surface methodology (rsm) approach. focus, 18, 19.

Diagne, A., Bamba, I., Manful, J. \& Ajayi, O. (2011). Historic opportunities for rice growers in nigeria. Inter-reseaux Department rural. Retrieved from http://www.interreseaux.org/revue-grain-de-sel/51-specialissue-nigeria/article/historic-oppotunitiesfor-rice?lang $=\mathrm{fr}$

Gariboldi, F. (1979). Rice testing methods and equipment. FAO Agricultural Services Bulletin.

Imolehin, E. D. \& Wada, A. C. (2000). Meeting the rice production and consumption demands of nigeria with improved technologies. International Rice Commission Newsletter, 49, 33-41.

Juliano, B. (1971). A simplified assay for milledrice amylose. Cereal Science Today, 16, $334-360$.

Muthayya, S., Sugimoto, J. D., Montgomery, S. \& Maberly, G. F. (2014). An overview of global rice production, supply, trade, and consumption. In L. M. DeRegil, A. Laillou, R. MoenchPfanner \& J. P. PenaRosas (Eds.), Technical considerations for rice fortification in public health (Vol. 1324, pp. 7-14). Annals of the New York Academy of Sciences. doi:10.1111/ nyas. 12540

Mutters, R. G. \& Thompson, J. F. (2009). Rice quality handbook. UCANR Publications. Retrieved from http://books.google.com. ng / books / about/rice_quality_handbook . html?id=ni4c73mfavuc\%5C\&redir_esc $=y$

Odenigbo, A. M., Ngadi, M., Ejebe, C., Woin, N. \& Ndindeng, S. A. (2014). Physicochemical, cooking characteristics and textural properties of tox 3145 milled rice. Journal of Food Research, 3, 82. doi:10.5539/jfr . v3n $2 \mathrm{p} 82$

Oko, A. O. \& Ugwu, S. I. (2011). The proximate and mineral compositions of five major rice varieties in abakaliki, south-eastern nigeria. 
Cooking properties of parboiled milled domestic rice |331

International Journal of Plant Physiology and Biochemistry, 3, 25-27.

Oko, A., Ubi, B. \& Nahemiah, D. (2012). Rice cooking quality and physico-chemical characteristics: A comparative analysis of selected local and newly introduced rice varieties in ebonyi state, nigeria. Food and Public Health, 2, 43-49. doi:10.5923/j.fph . 20120201.09

Sanusi, M. S., Akinoso, R. \& Danbaba, N. (2017). Evaluation of physical, milling and cooking properties of four new rice (oryza sativa l.) varieties in nigeria. International Journal of Food Studies, 6(2).

Singh, N., Kaur, L., Sodhi, N. S. \& Sekhon, K. S. (2005). Physicochemical, cooking and textural properties of milled rice from different indian rice cultivars. Food Chemistry, 89(2), 253-259. doi:10.1016/j. foodchem. 2004.02.032

Thomas, R., Wan-Nadiah, A. W. \& Bhat, R. (2013). Physiochemical properties, proximate composition, and cooking qualities of locally grown and imported rice varieties marketed in penang, malaysia. International Food Research Journal, 20, 16791685.

Webb, B. D. (1972). Criteria of rice quality. Rice: Chemistry and technology, 102-139.

Yadav, R. B., Khatkar, B. S. \& Yadav, B. S. (2007). Morphological, physicochemical and cooking properties of some indian rice (oryza sativa 1.) cultivars. Journal of Agricultural Technology, 3(2), 203-210. 